\title{
Accelerating Energy Transition to Green Electricity through Artificial Intelligence

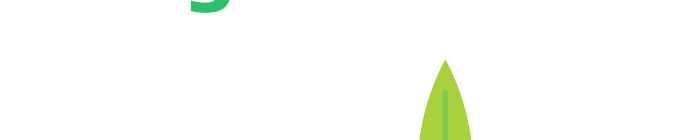

\section{Hendro Wicaksono}

Professor of Industrial Engineering, Jacobs University Bremen

President Commisioner PT Labdha Teknika Nusantara (GreenIndonesia) 


\section{Contents}

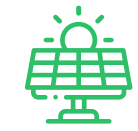

\section{Part 1}

Challenges in transition to green electricity

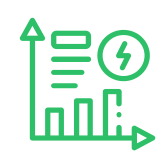

\section{Part 4}

The roles of data analytics in demand response

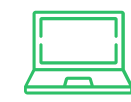

\section{Part 2}

Digitalization in energy transition

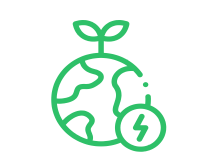

\section{Part 5}

The roles of data management in smart energy systems of smart cities

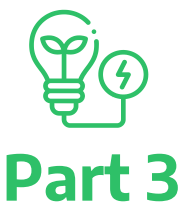

Demand response and dynamic price 


\section{Part 1 \\ Challenges in transition to green electricity}




\section{Goals of Germany's energy transition}
2020
40\% less greenhouse gas emissions
2022
Shutdown of the last nuclear power plants
2025
40-45\% share of renewable energies in electricity consumption
2050
$50 \%$ less primary energy consumption 


\section{Electricity mix first semester 2020}

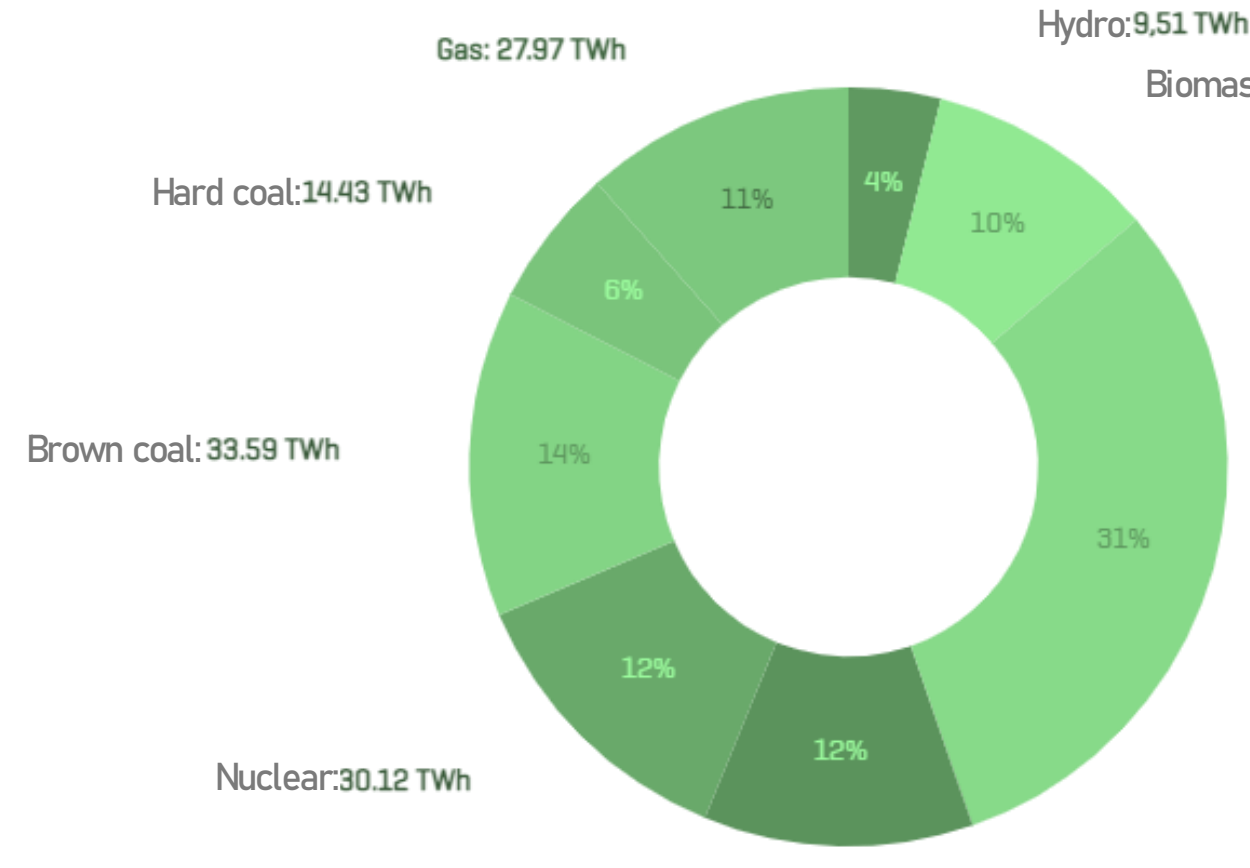

Solar: 27.87 TWh
Proportion of green electricity: $57 \%$ 


\section{Electricity price in Germany}

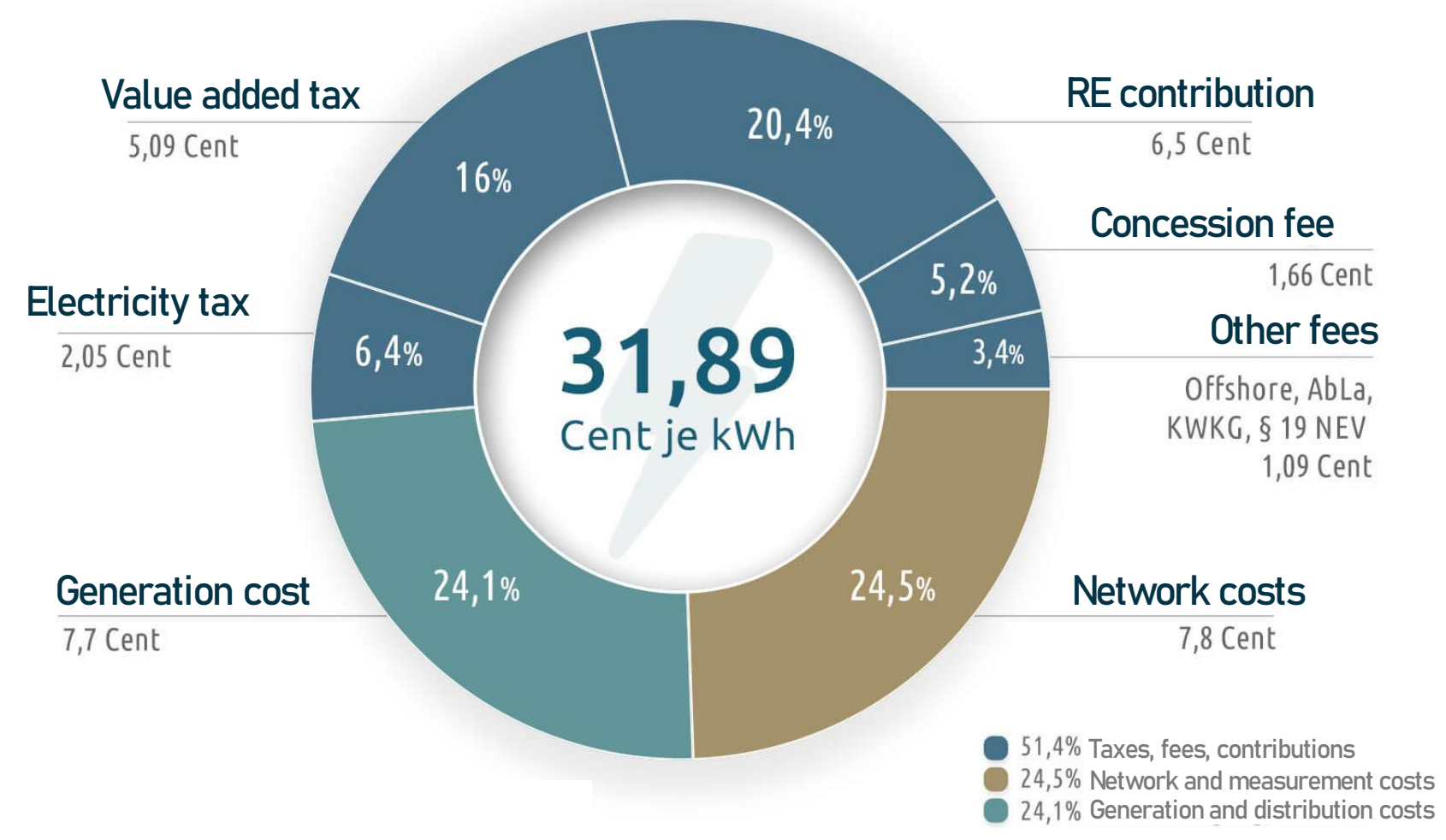




\section{Electricity price development in Germany}

2012

2014

2016

2018

2020

2021

30

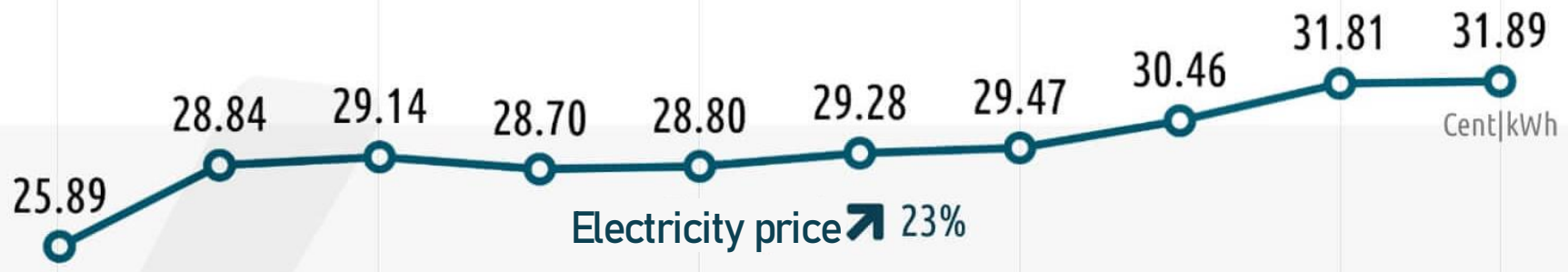

Tax and contributions $741 \%$

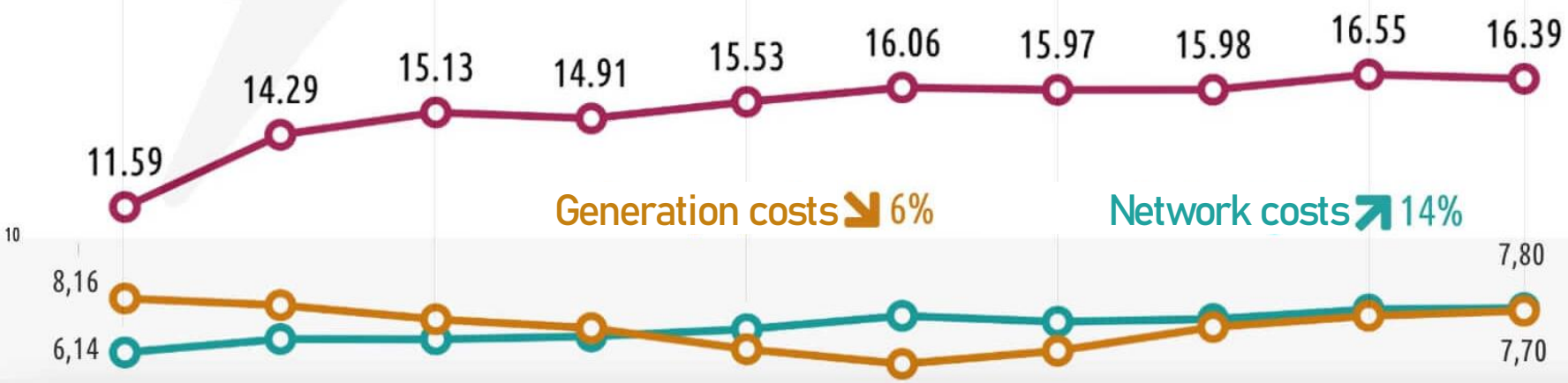




\section{Challenges in adoption of green electricity}

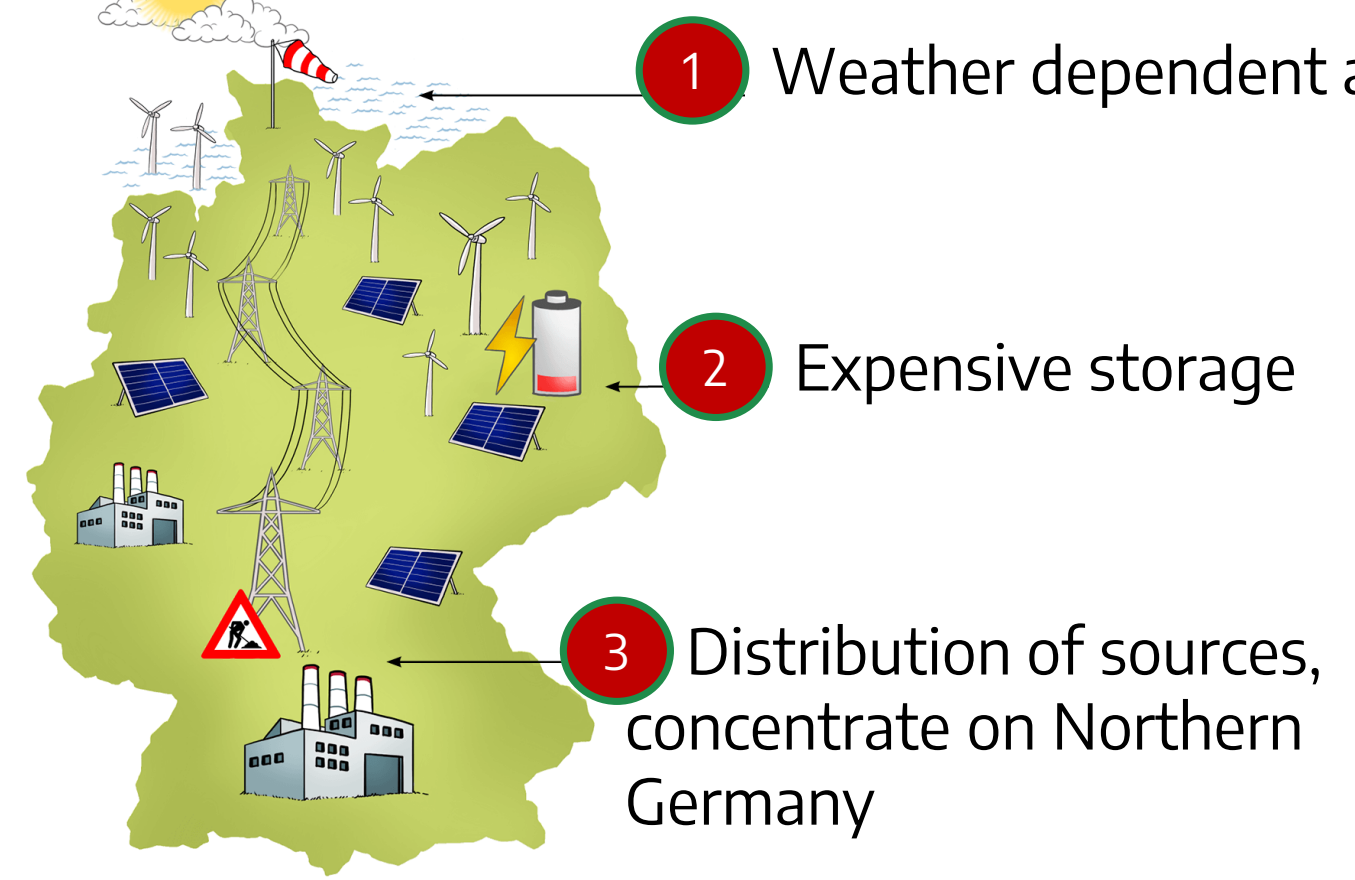




\section{Requirements for a functioning energy transition}

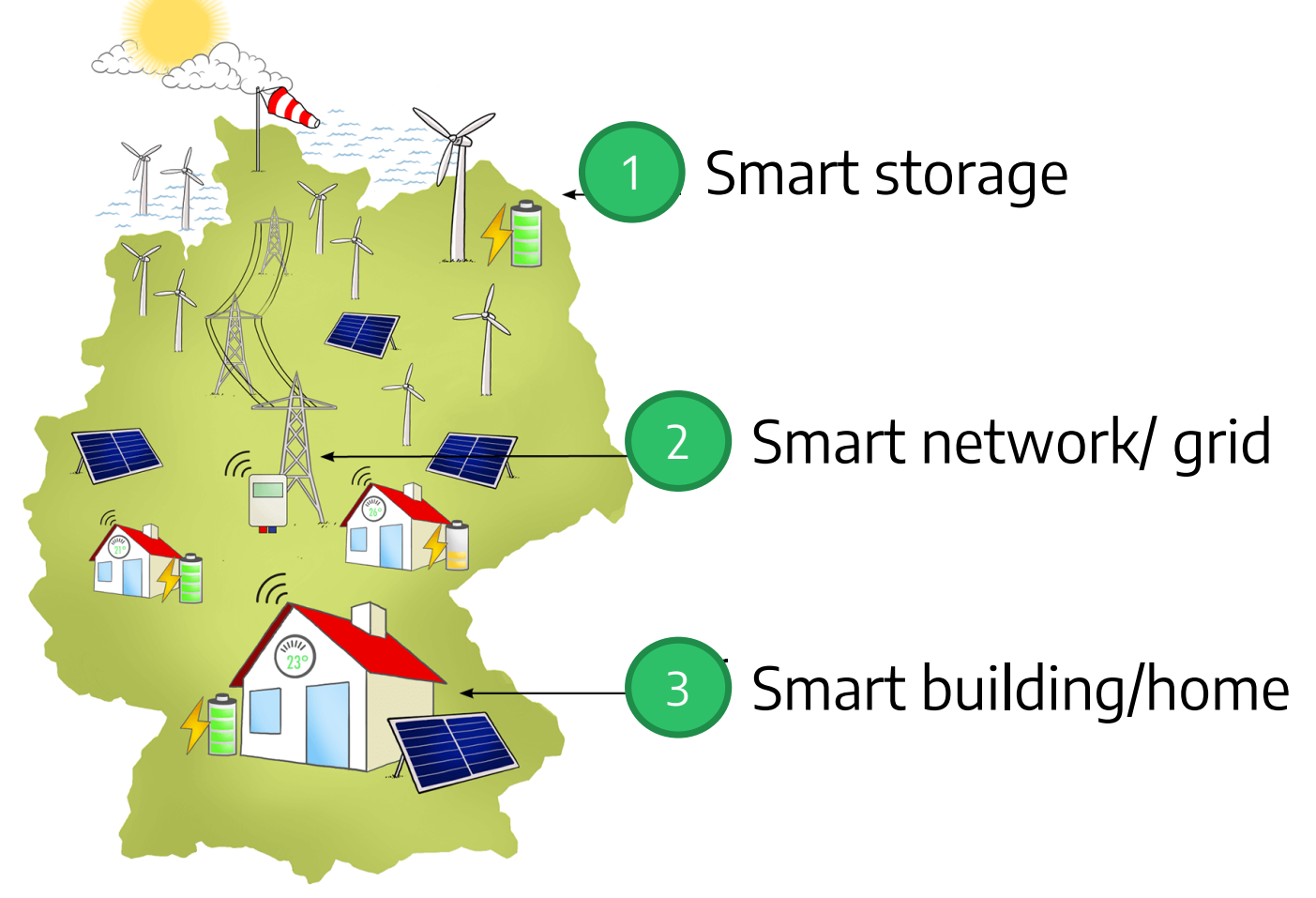




\section{How to enable and accelerate energy transition?}




\section{Part 2 Digitalization in energy transition}




\section{Digitalization dimension}

\section{Methods}

- Internet of Things

- Artificial intelligence

- Big data computing

- Digital twin

- Blockchain

\section{Applications}

- Data analysis

- Operation and regulation

- Automation

\section{Data storage and processing}

- Local (edge computing)

- Centralized (cloud computing)

- Mixed

\section{Application fields}

- Energy industry

- Generation

- Network

- Consumption

- System component in manufacturing 


\section{Cross sectoral digitalization of energy transition}

for cross-sector digitalization of energy transition

\section{Cluster 1}

\section{Smart Metering/}

Sub Metering

Flexible tarif, multidisciplinary measurements

\section{Cluster 2}

\section{Smart Grid}

Feed-in, load, and energy management

\section{Smart Mobility}

Charging station infrastructure, charging management

\section{Cluster 3}

\section{Smart Services}

Building

Housing management
Assisted living, Value added services 


\section{Smart Meter: the required digitalization infrastructure}

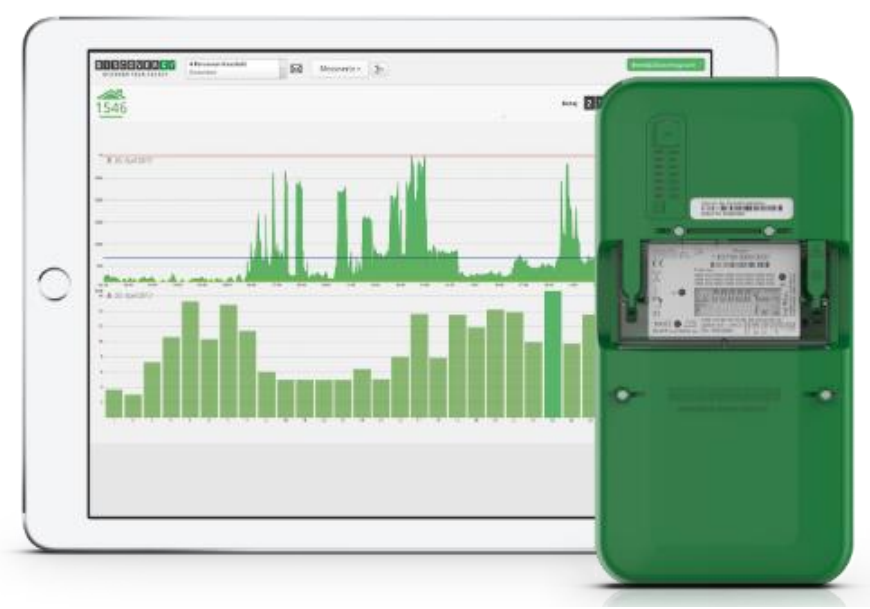

Image: discovergy.com

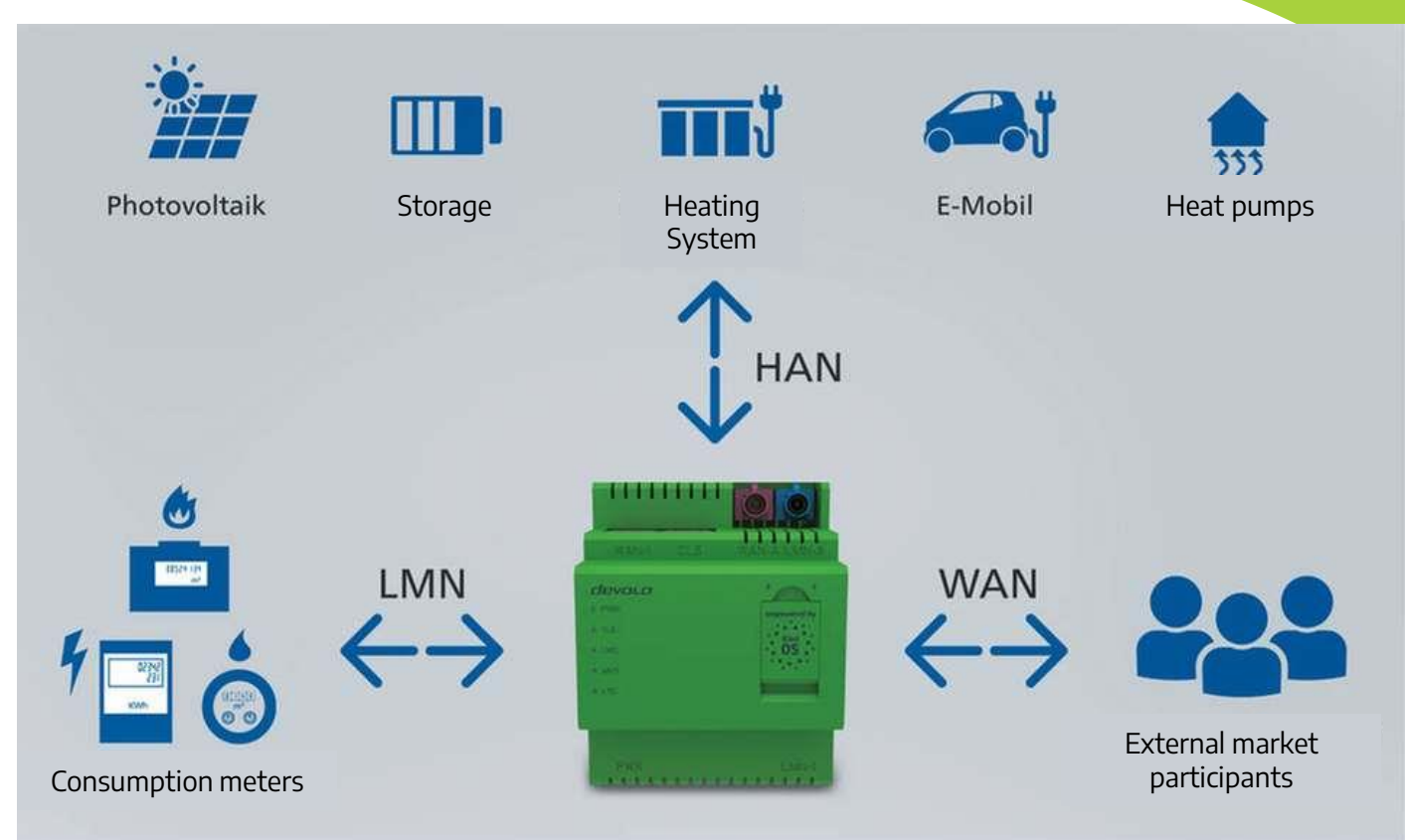

Image: devolo 


\section{Energy management system using}

smart meter
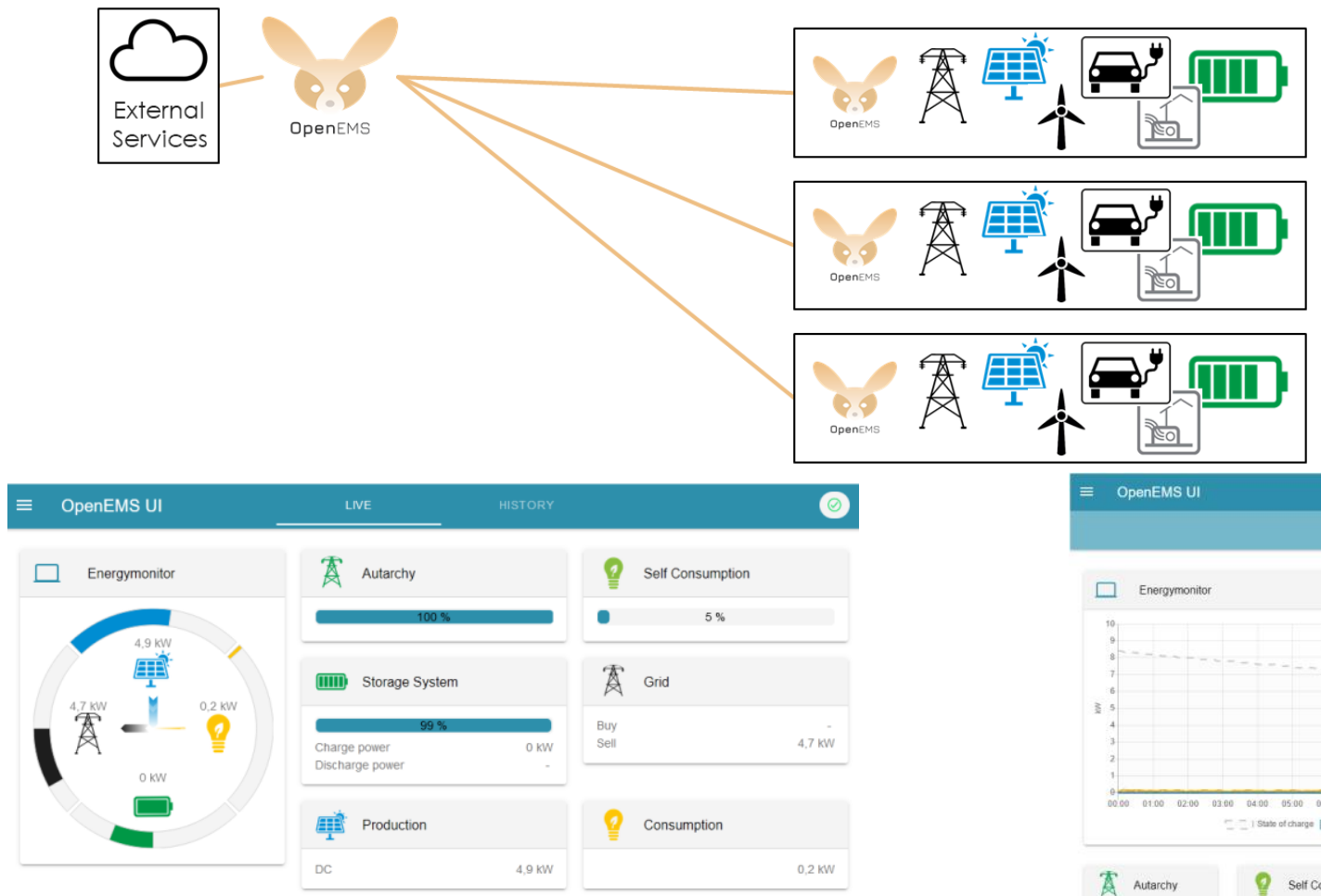

๑

=

operensur

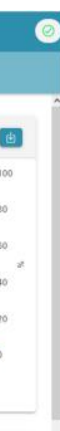


How to make consumers take part in energy transition? 


\section{Part 3}

Demand response

and dynamic price 


\section{Demand Response}

"Demand Response is changes in electric usage by end-use customers from their normal consumption patterns in response to changes in the price of electricity over time, or to incentive payments designed to induce lower electricity use" 


\section{Why Demand Response?}

- The goal of Demand Response is to shift the peak demand (red) to the peak time of availability of renewable energies (yellow).

- The power consumption is shifted from red to green, (green) shows the decrease of energy waste.

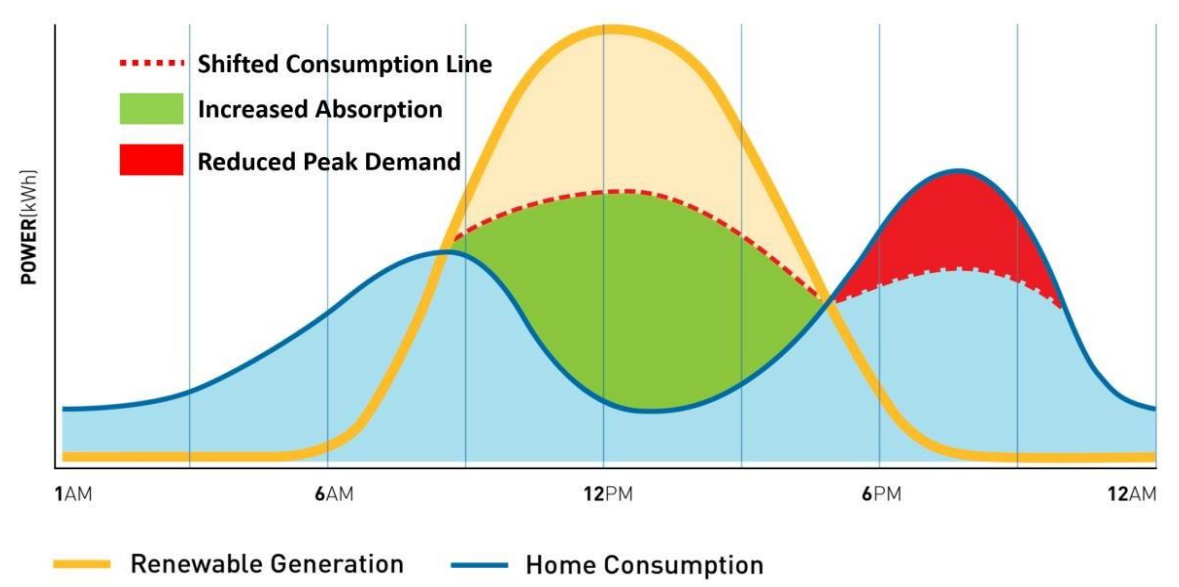

DR has the potential to access $160 \mathbf{G W}$ of flexible capacity by $\mathbf{2 0 3 0}$. This reduces energy supply costs by up to $\mathbf{5 0}$ billion euros. 


\section{The transformation of generation-consumption relationships}

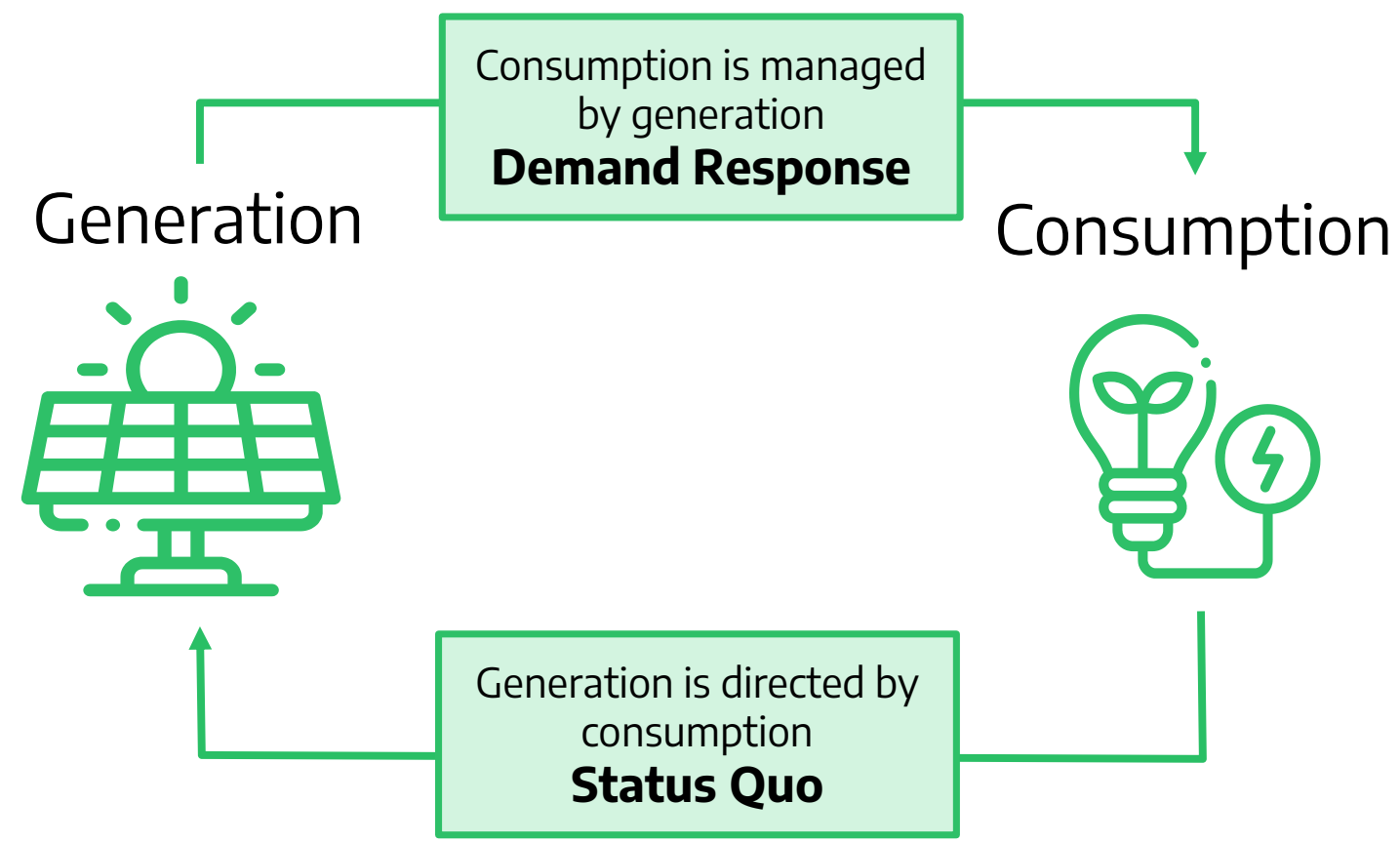




\section{Automated demand response}

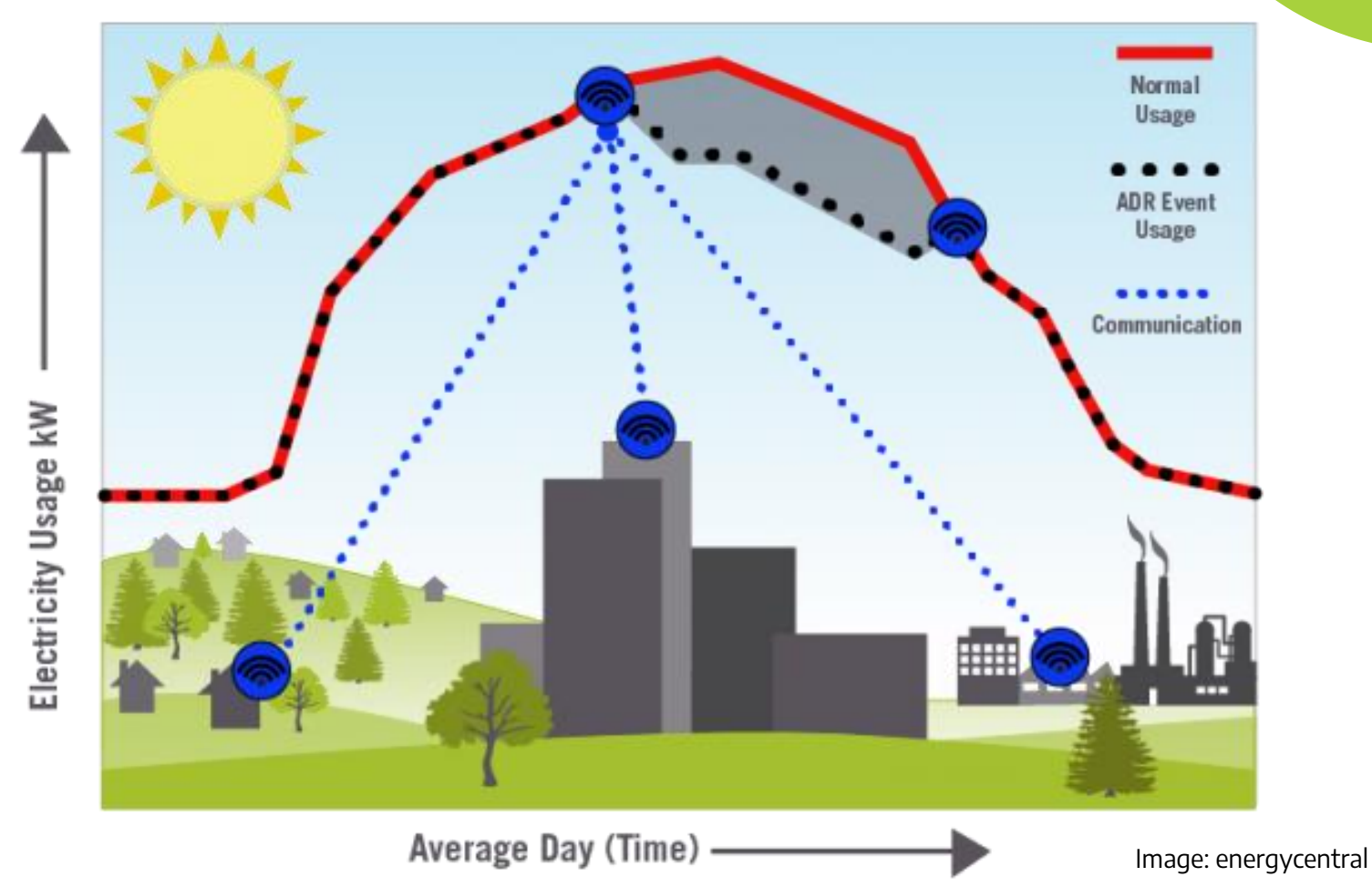




\section{Time variable electricity tarif}

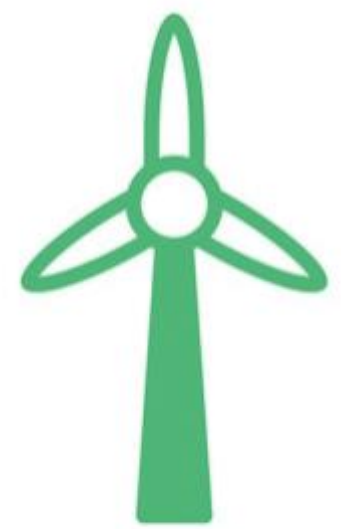

a lot of wind

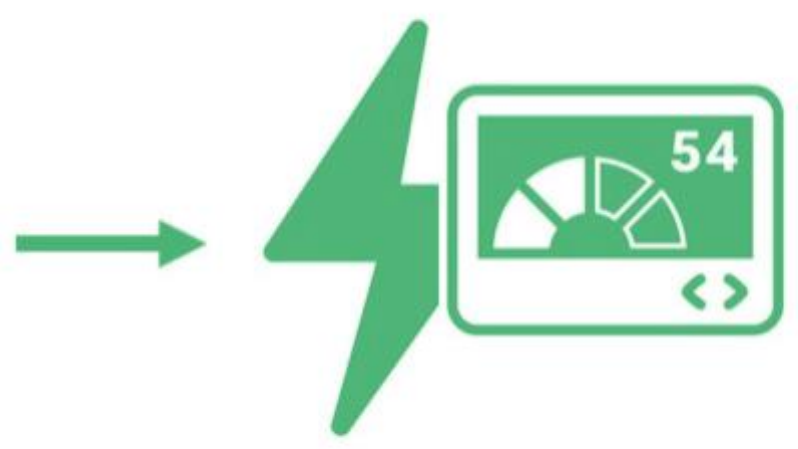

a lot of available electricity

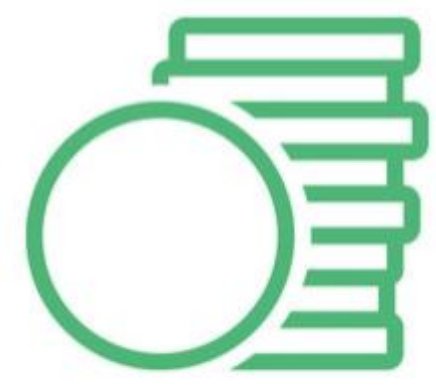

cheaper electricity 


\section{Dynamic price implementations in different countries}

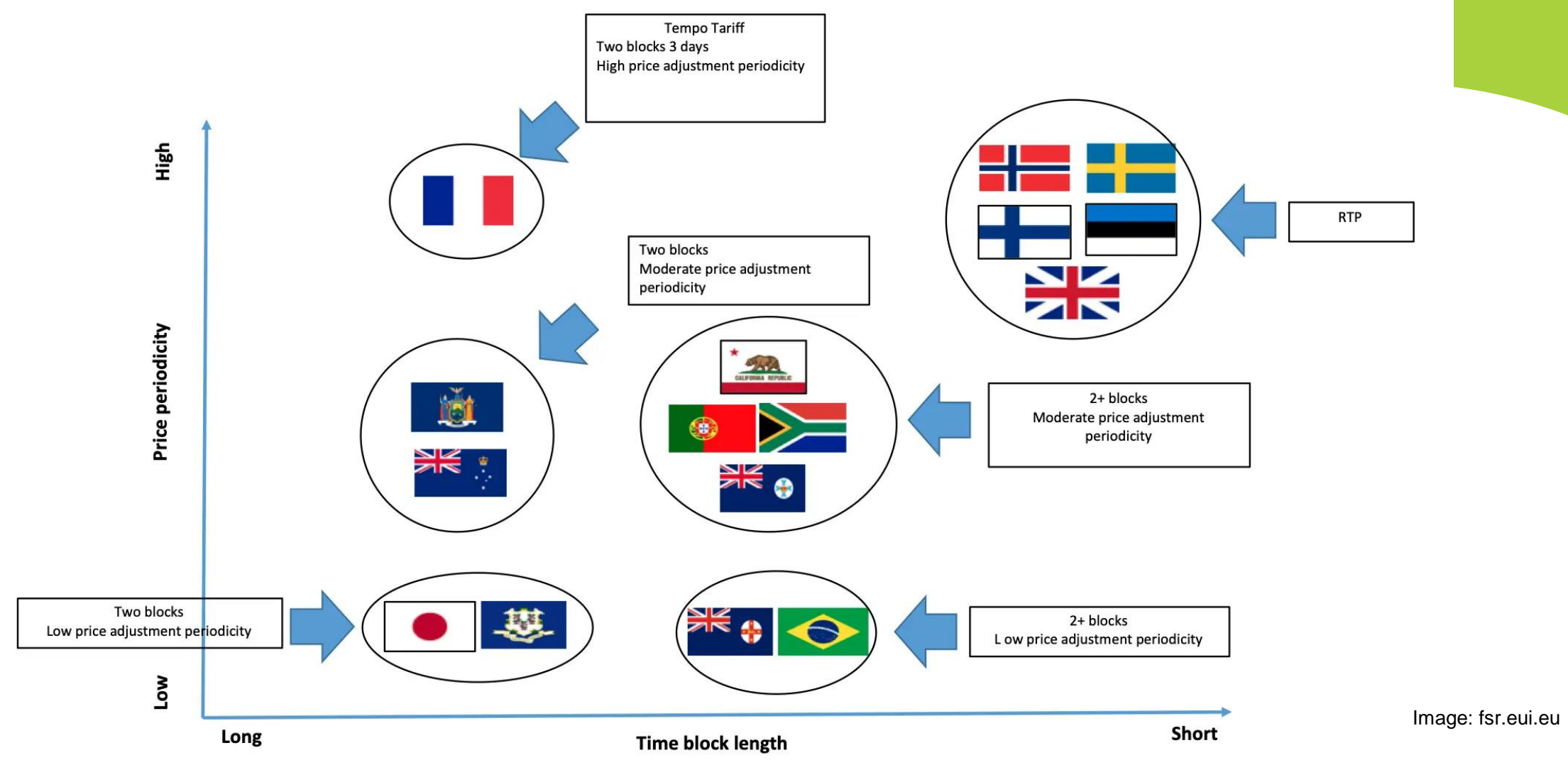




\section{How to implement DR and what are the roles of artificial intelligence?}




\section{Part 4}

The roles of data analytics in demand response 


\section{Delfrne}

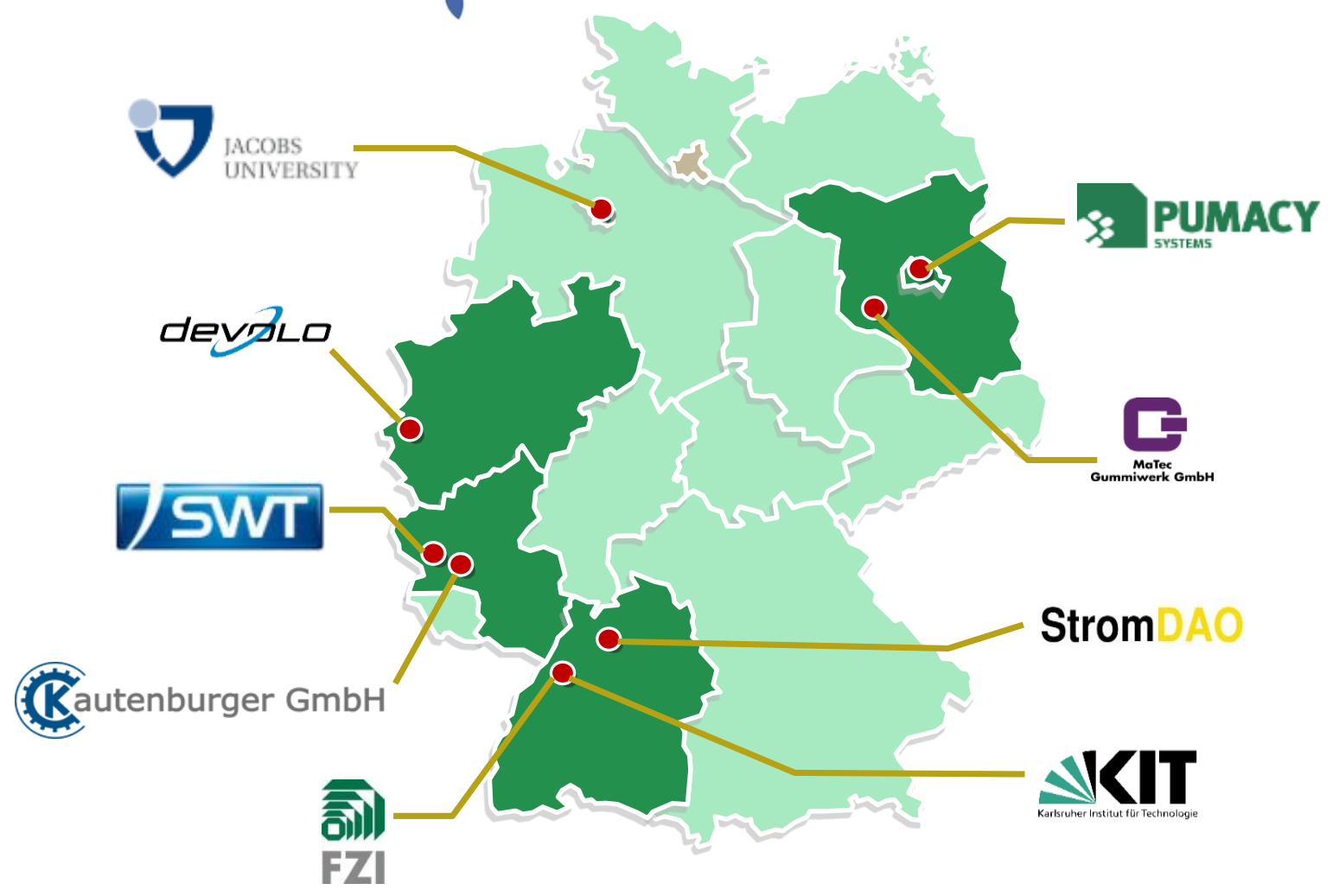




\section{Project concept}

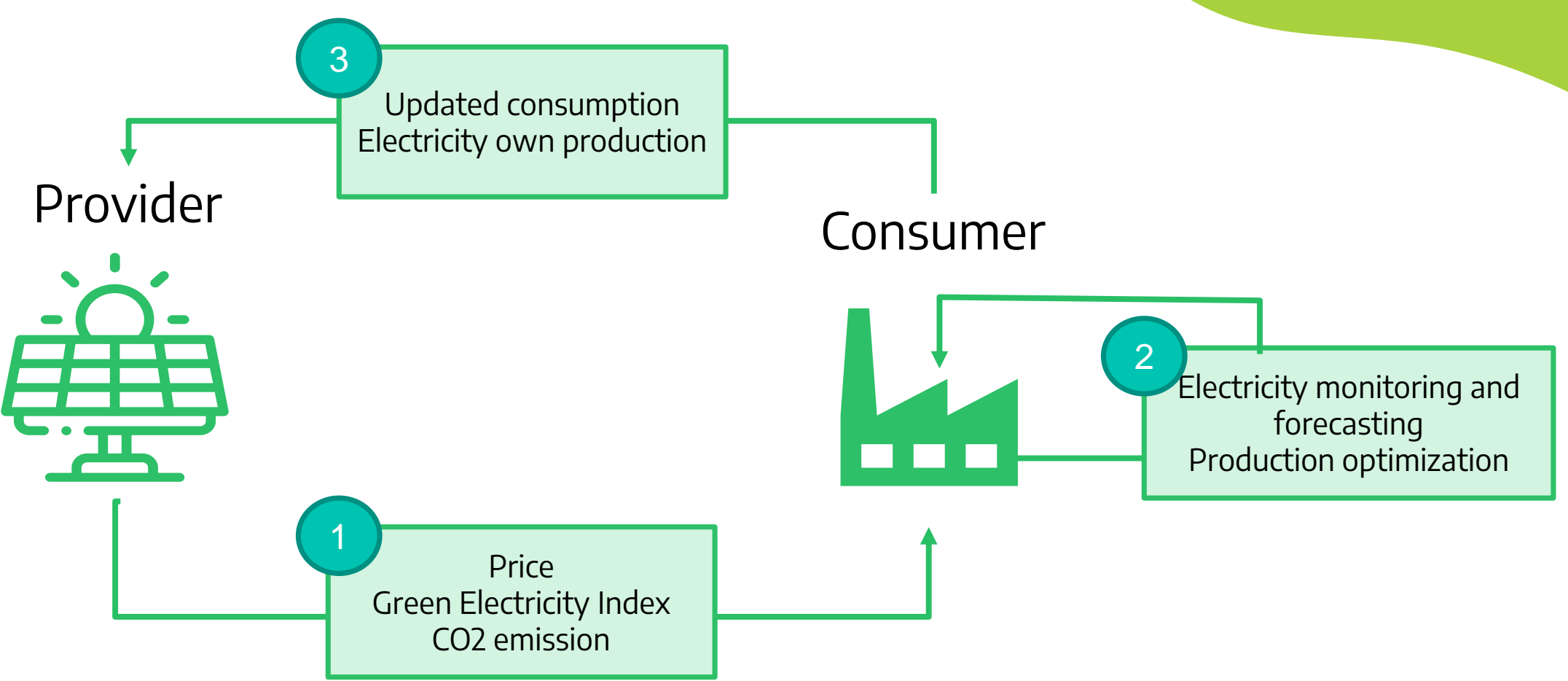




\section{Solution approach}

\section{Provider}

\section{Cloud}

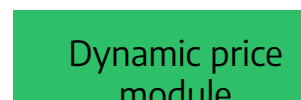
module

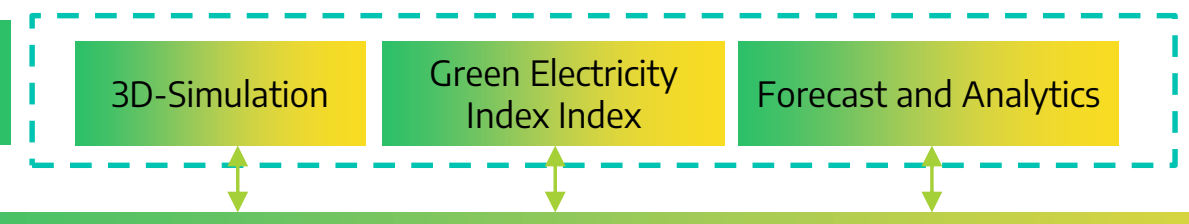

\section{Consumer}

Production optimization

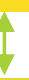

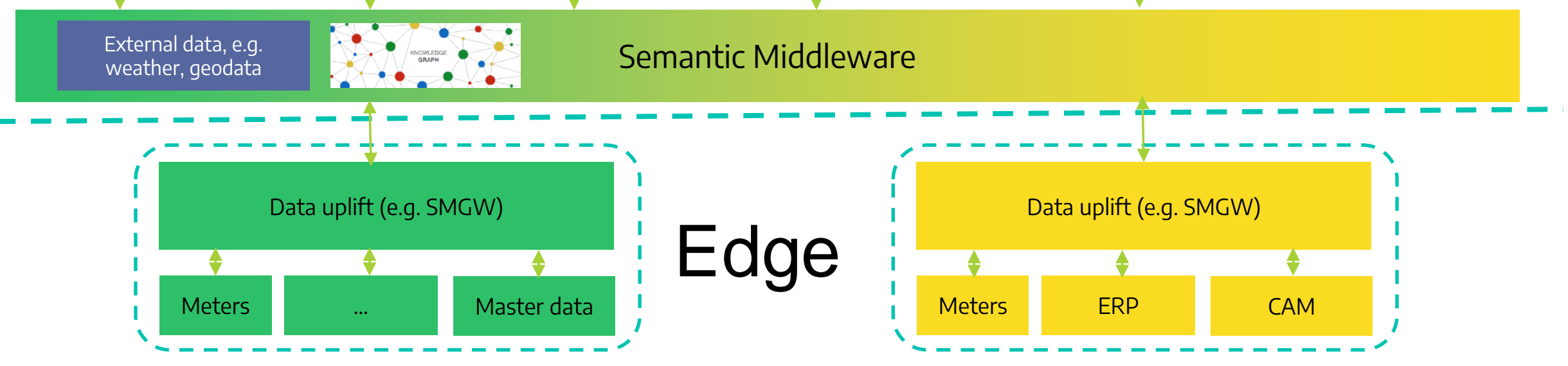




\section{Green electricity index}

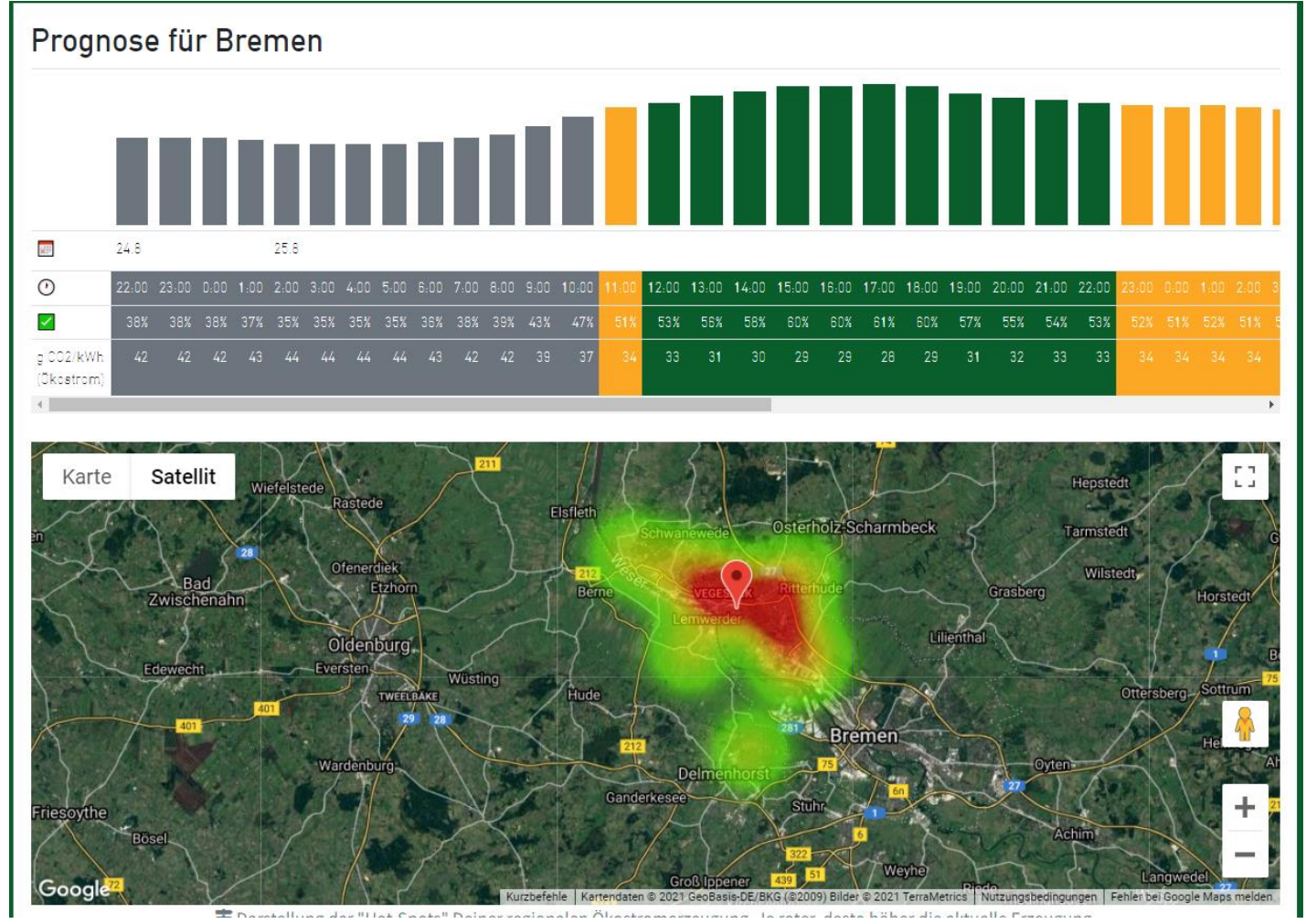

https://corrently.de///gruen stromindex.html?plz=2875 9 


\section{Forecast of green electricity generation}

Deep Neural

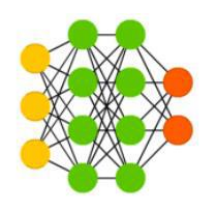

Long Short

Term Memory

(LSTM)

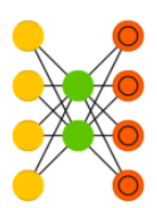

Wind
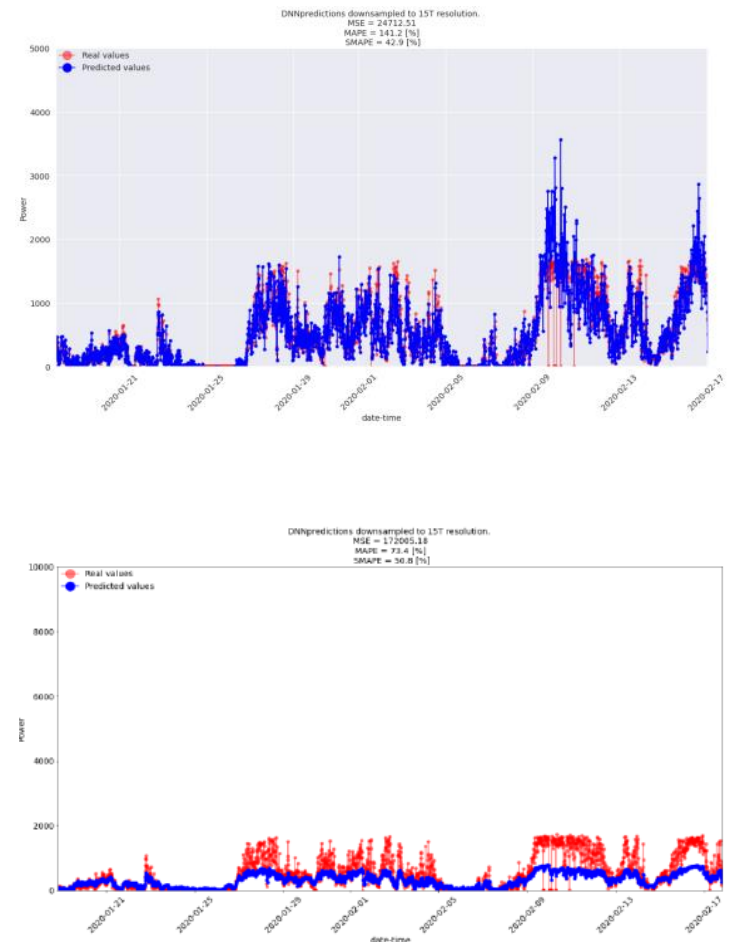

Solar

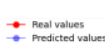

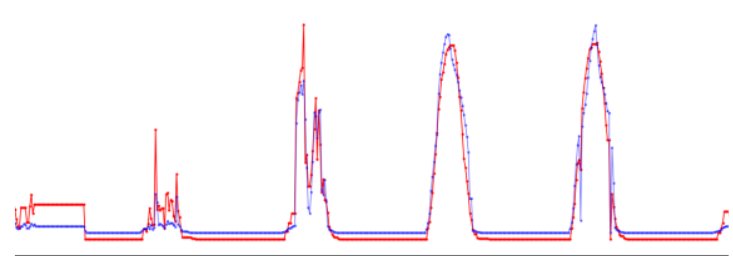

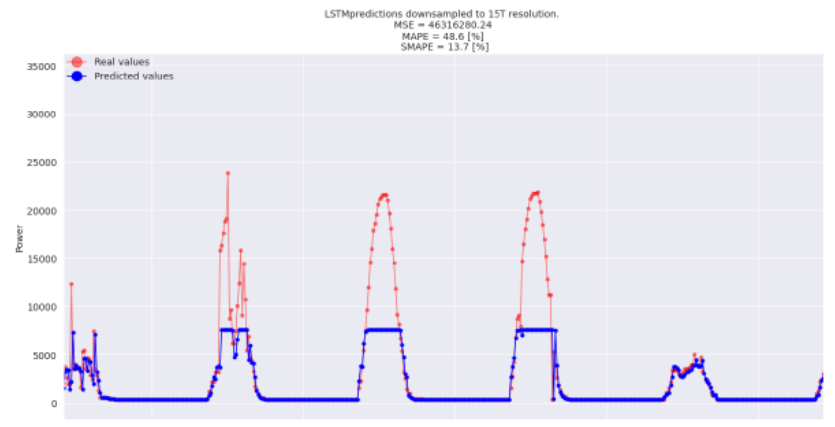




\section{Forecast of green electricity generation}

\section{Convolutional neural network}

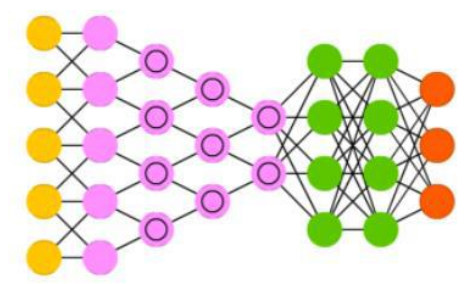

CNN-LSTM-DNN Hybrid

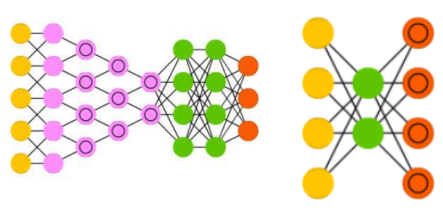

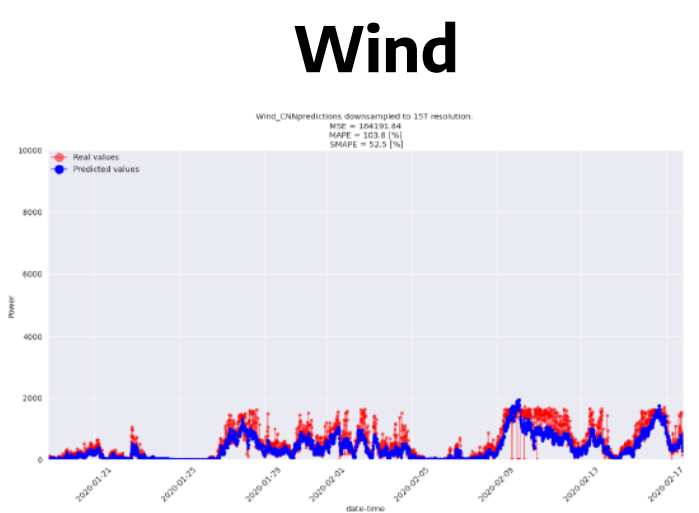

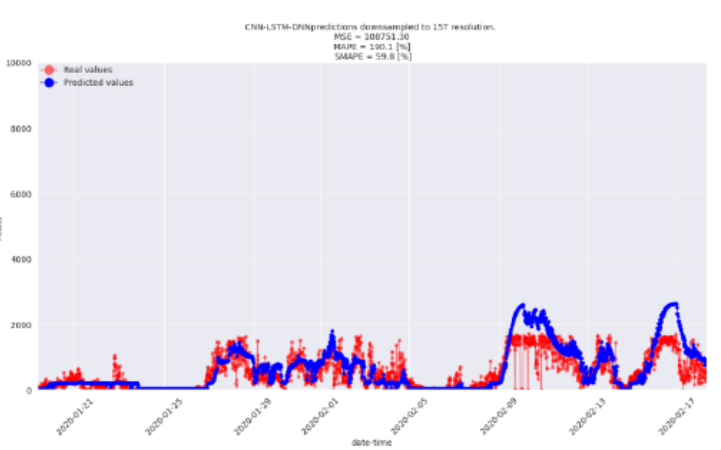

Solar
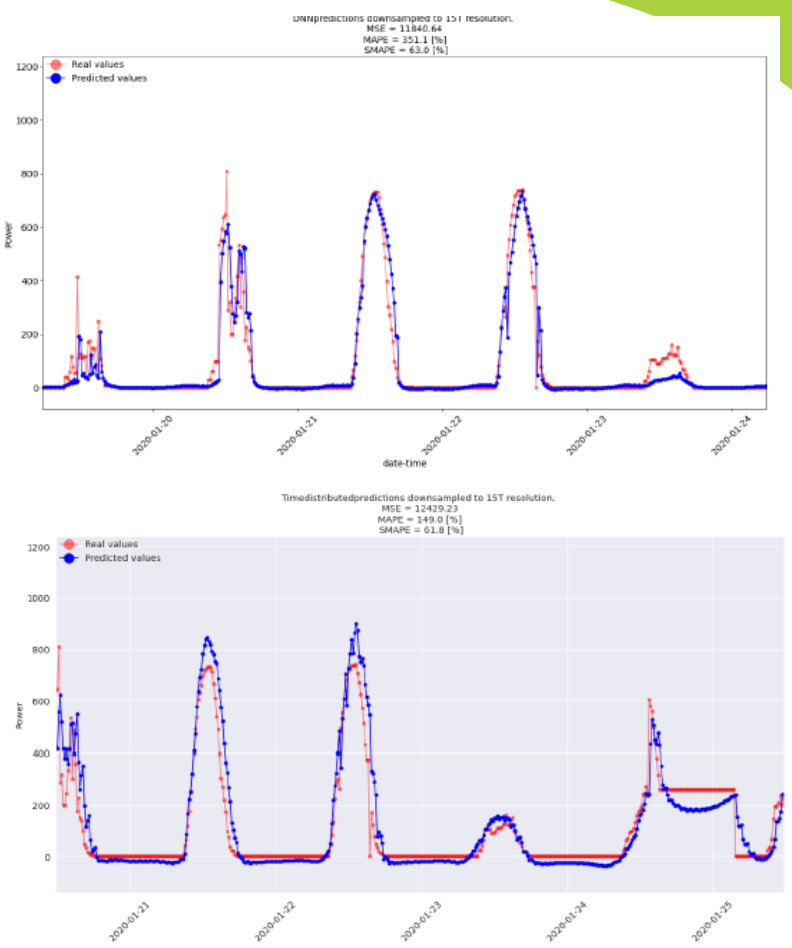


\section{ANN Model Evaluation}

\begin{tabular}{|c|c|c|}
\hline ANN Model & $\begin{array}{l}\text { MSE (Short-term } \\
\text { forecast) }\end{array}$ & $\begin{array}{l}\text { MSE (Long-term } \\
\text { forecast) }\end{array}$ \\
\hline \multirow[t]{2}{*}{ DNN } & - Wind : $24 \mathrm{e} 3$ & - Wind:50e8 \\
\hline & - Solar:58e2 & - Solar:78e7 \\
\hline LSTM & $\begin{array}{l}\text { - } \quad \text { Wind : } 17 \mathrm{e} 4 \\
\text { - } \quad \text { Solar : 46e6 }\end{array}$ & $\begin{array}{l}\text { - } \quad \text { Wind : 71e9 } \\
\text { - } \quad \text { Solar : 48e12 }\end{array}$ \\
\hline CNN & $\begin{array}{l}\text { - Wind: } 18 \mathrm{e} 4 \\
\text { - Solar:11e3 }\end{array}$ & $\begin{array}{l}\text { - Wind:73e9 } \\
\text { - Solar: 83e8 }\end{array}$ \\
\hline \multirow[t]{2}{*}{ CNN-LSTM-DNN Hybrid } & - Wind:10e3 & - Wind: $46 \mathrm{e} 8$ \\
\hline & - Solar:12e3 & - Solar:15e8 \\
\hline
\end{tabular}

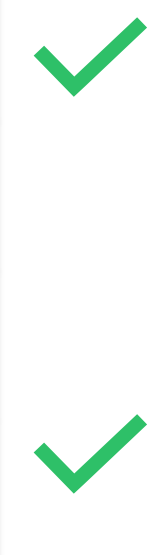




\section{How to utilize data to enable energy transition on a larger scope?}




\section{Part 5}

The roles of data management in smart energy systems of smart cities 


\section{A DAREED}

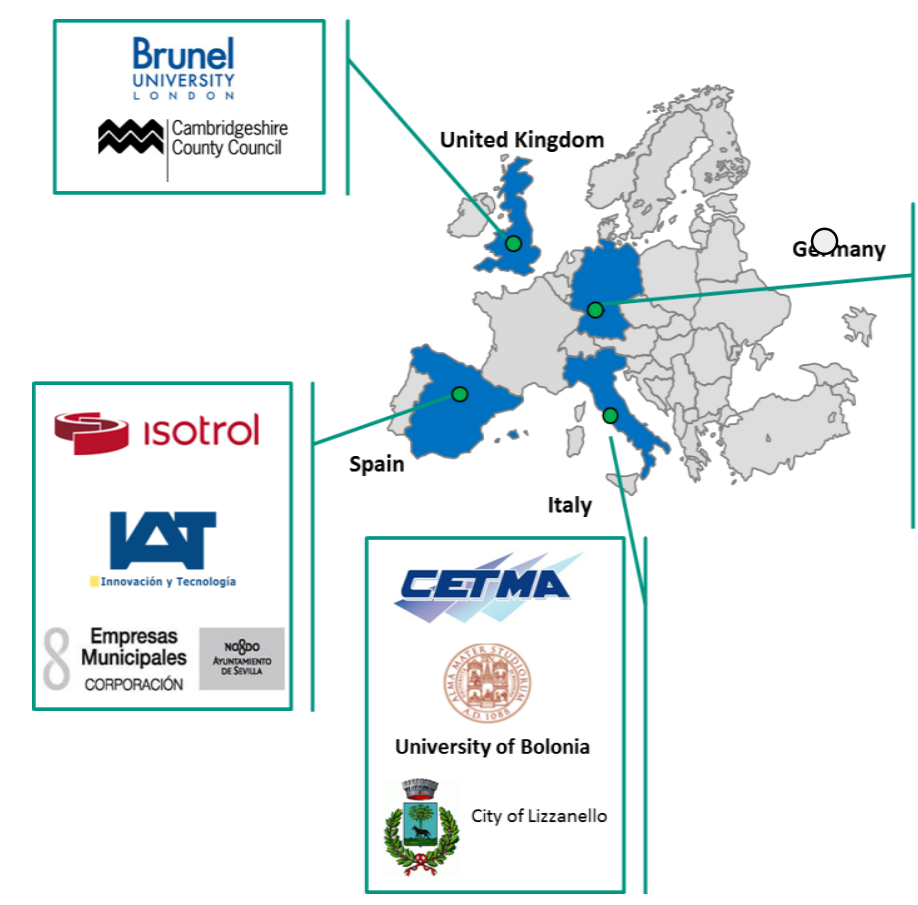

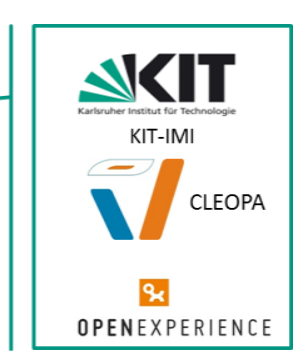

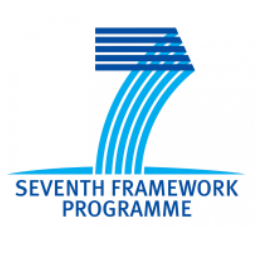

Cambridge, UK

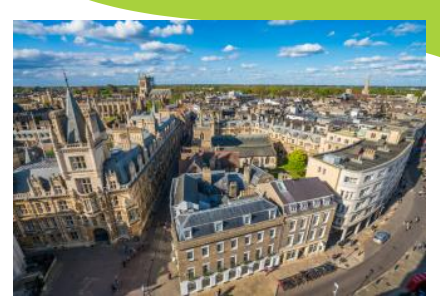

Seville, Spain

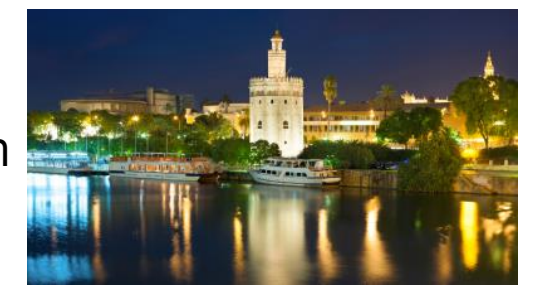

Lizanello, Italy

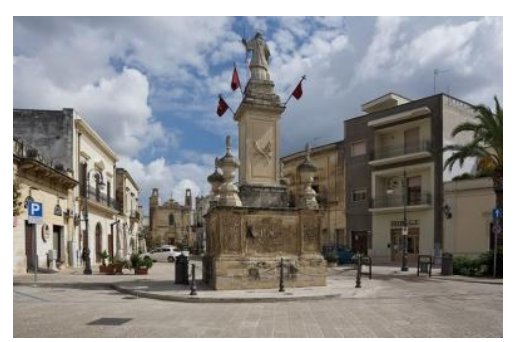




\section{DAREED: Smart energy platform}

A platform for main actors of energy management in cities and communities

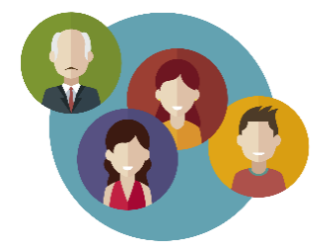

Citizen

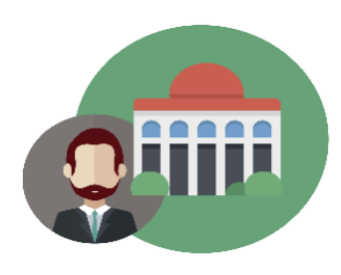

Policy maker

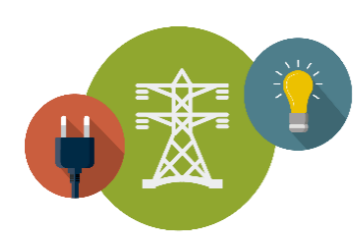

Energy provider and related industry

Platform = Data sharing + Integrated GUI and Single Sign-on + continuous/integrated process + individualized applications 


\section{Continuous data flow in the platform}

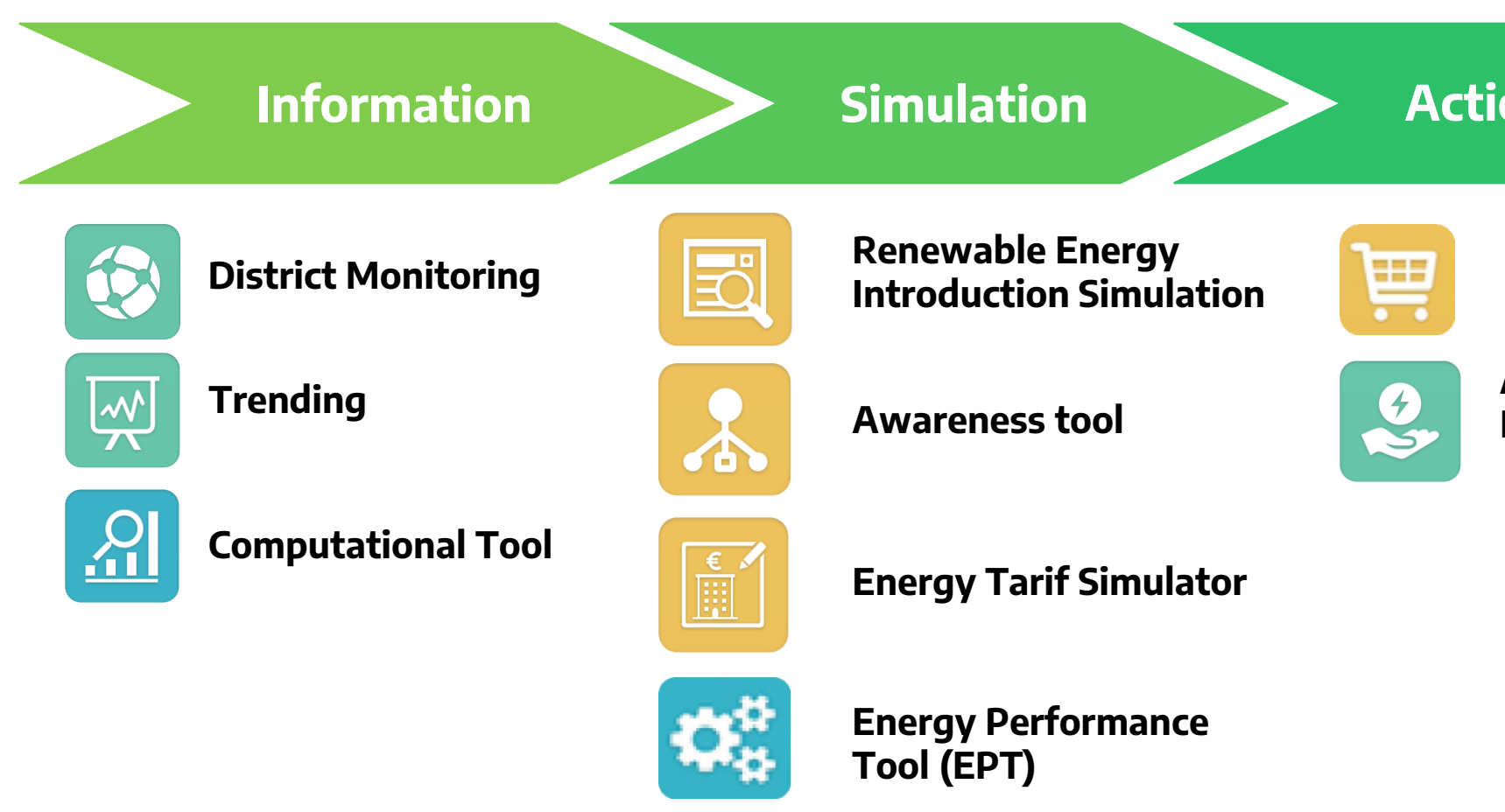

Marketplace

Active Demand Management 


\section{DAREED applications}
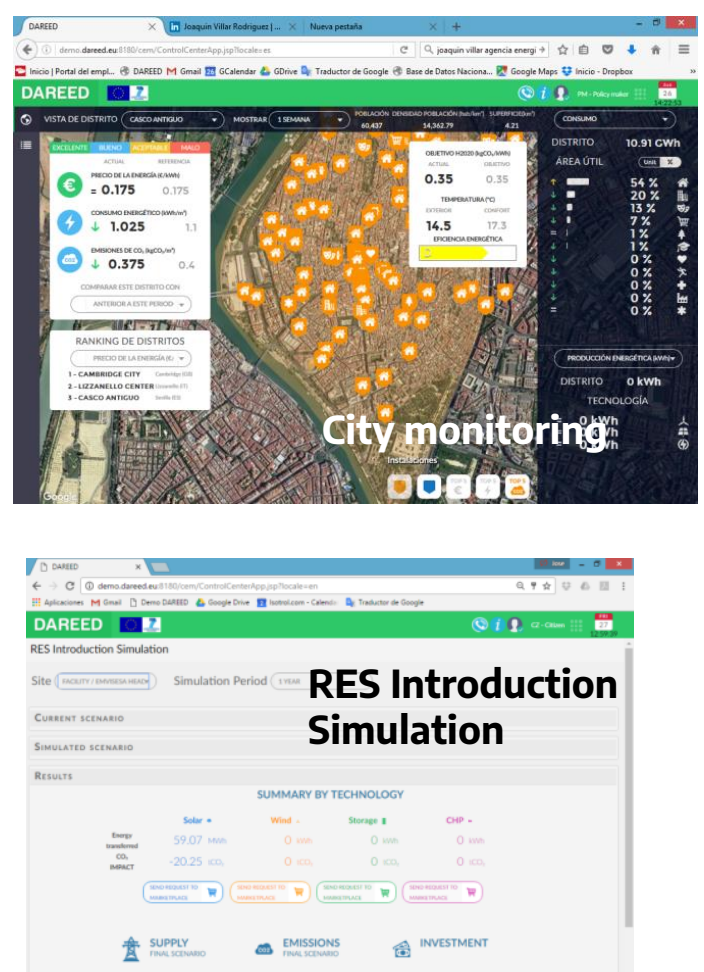
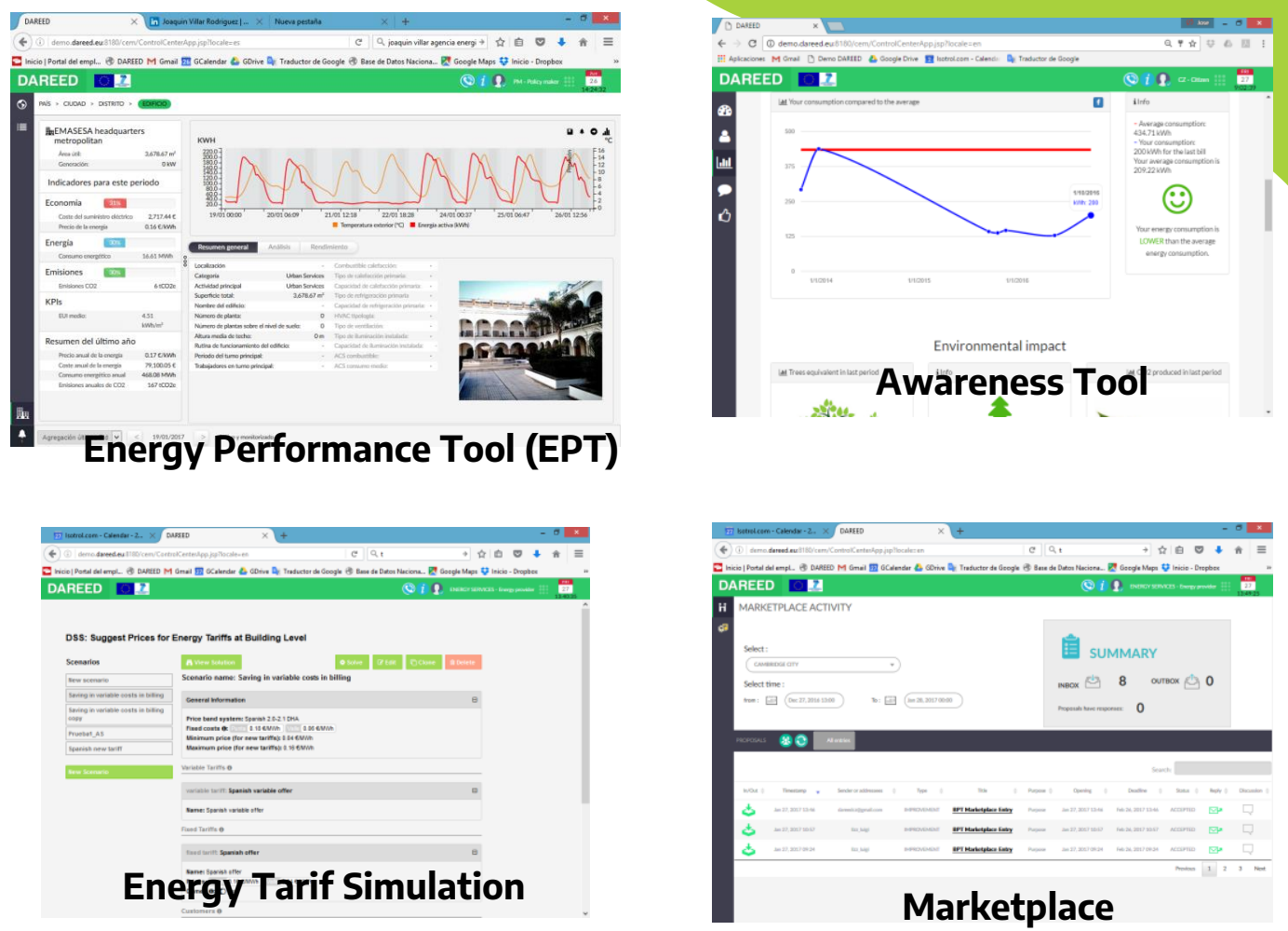


\section{Thank You!}

Do you have any questions?

h.wicaksono@jacobs-university.de

hendro.wicaksono@green-Indonesia.com

https://green-indonesia.com/\#/home

http://indeed.user.jacobs-university.de/

+4917623910735 @greenindonesiaofficial

@hendro.wicaksono.9

@Indeed)acobsUniversity

@greenindonesiaofficial

@hendro_002

@hendrowicaksono

CREDITS: This presentation template was created by Slidesgo, including icons by Flaticon, and infographics \& images by Freepik 